\title{
Knowledge and attitude toward AIDS among people admitted to the Qazvin faculty of Dentistry (2014)
}

\author{
$\underline{\text { M. Zarabadipour }}^{1}$, K. Borhan-Mojabi ${ }^{1}$, B. Saboor Bagherzadeh ${ }^{2}$, F. Mozaffari ${ }^{2}$
}

\author{
${ }^{1}$ Dental Caries Prevention Research Center, Qazvin University of Medical Sciences, Qazvin, Iran \\ ${ }^{2}$ Student Research Committee, Faculty of Dentistry, Qazvin University of Medical Sciences, Qazvin, Iran \\ Corresponding Address: Mahdieh Zarabadipour, Dental Caries Prevention Research Center, Dental faculty, Qazvin \\ University of Medical Sciences, Bahonar Blvd., Qazvin, Iran \\ Tel: +98-28-33353064, Email: mahdieh.zarabadi@gmail.com \\ Received: 14 May 2017; Accepted: 18 Sep 2017
}

\section{* Abstract}

Background: AIDS is as a global fatal disease and the only way to combat the disease is education and knowledge about the methods of transmission and prevent of the disease.

Objective: The aim of this study was to evaluate the knowledge and attitudes of people admitted to the Qazvin faculty of Dentistry toward AIDS.

Methods: A cross-sectional descriptive study was conducted in 2013-2014 using a standard questionnaire between 270 people admitted to the Qazvin faculty of Dentistry.

Findings: According to data analysis, 150 subjects (55.6\%) had a poor knowledge about the disease and with increasing the age, knowledge was lower. The attitude of 153 subjects $(56.7 \%)$ was moderate. All the participants were married and had 20 years old at least.

Conclusion: This study indicated that the knowledge and attitude of people admitted to the Qazvin faculty of Dentistry was inappropriate and there was a necessity to promote absolute knowledge and good attitude about AIDS.

Keywords: Knowledge, Attitude, AIDS

Citation: Zarabadipour M, Borhan-Mojabi K, Saboor Bagherzadeh B, Mozaffari F. Knowledge and attitude toward AIDS among people admitted to the Qazvin faculty of Dentistry (2014). J Qazvin Univ Med Sci 2018; 22(1): 87-91. 


\section{برر سى دانش و نكَرش بيماران مراجعه كننده به دانشكده دندانيزشكى قزوين درباره ايدز (اس (1)}

دكتر مهديه زرآبادىيور '، دكتر كتايون برهان مجابى'، دكتر بهاره صبور باقرزاده'، فاطمه مظفرى'

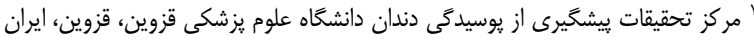

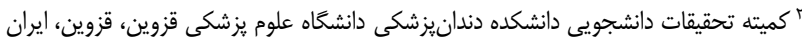

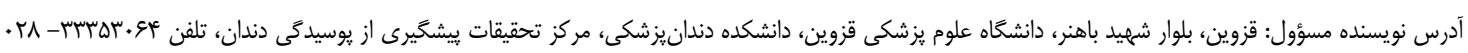
تاريخ دريافت: (

زمينه: بيمارى ايدز بهصورت يكى بيمارى مهلك جهانى مىباشد و تنها راه مبارزه با بيمارى، شناخت راههاى انتقال و روشهـاى ييشـحيرى اسـت.

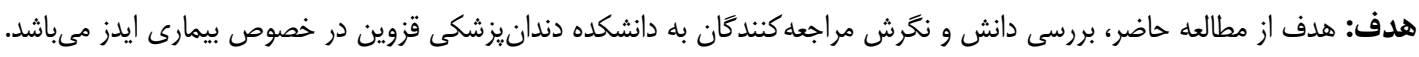

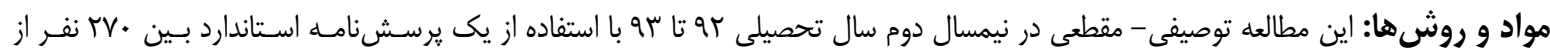

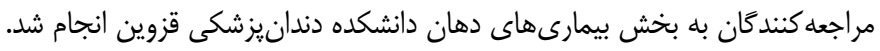

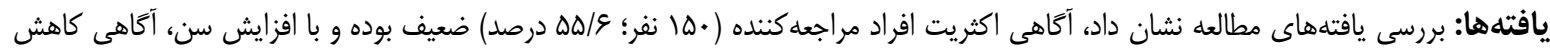

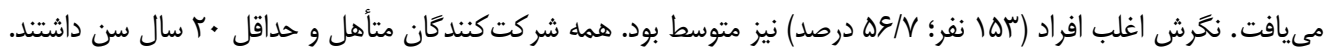

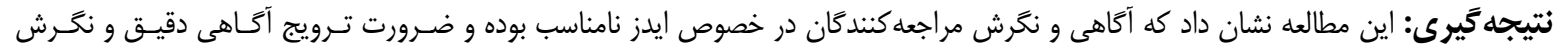
مناسب درباره ايدز وجود دارد.

كليدوازهها: آَاهى، نخرش، ايدز

مقدمه:

نظير رابطه جنسى محافظت نشده، داشـتن هنـــ شـريك جنسى، عدم اسـتفاده يـا اسـتفاده غيرمــاوم از كانـدوم و اعتيـاد دارويسى سـالامت نوجوانـان و بـالغين جـوان را در معرض خطر ابتلا به ايدز و ديخر بيمارى هاى منتقله از راه

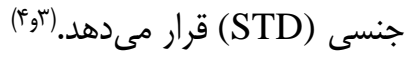
يك عامل مهم انتشـار ايسدز در كشـورهاى در حـال

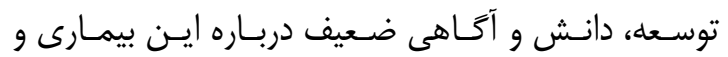
راههاى ييشخيرى و روش هاى انتقال آن اسـت. همجنـين در اكثر مواقع، دانش و نـخرش در مواجهه با افراد آلوده بــهـ

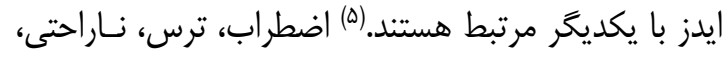

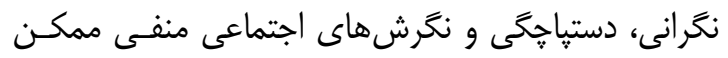

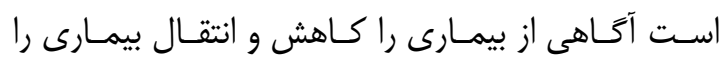
تسميل نمايد.(اوr) هدف از اين مطالعه، بررسى ميزان آكاهى

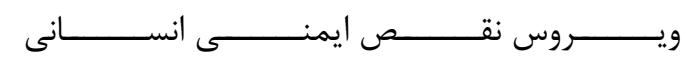

كــ (Human Immunodeficiency Virus, HIV)

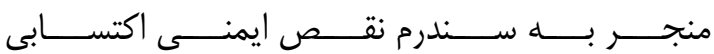
(Acquired Immunodeficiency Syndrome, AIDS) مىشود، نخستين بار سال (191 در آمريكا شناخته شـد و ظرف مدت كوتاهى بلصورت يك بيمارى شايع و مهلـى

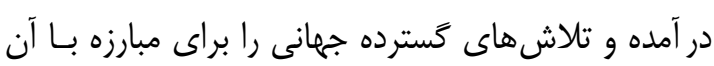

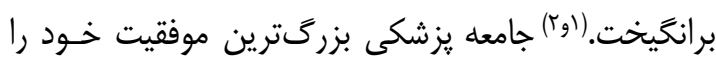

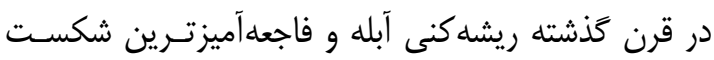

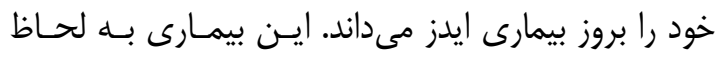

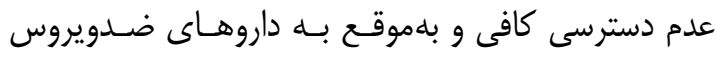
عليه ويروس ايدز در كشورهاى در حال توسعه همـواره از

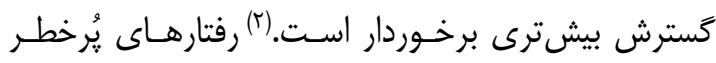




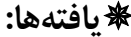

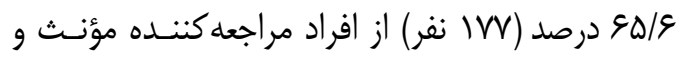

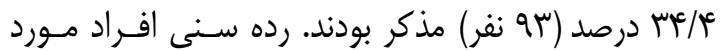

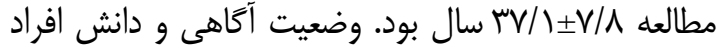
مورد بررسى در جدول ا عنوان شده است.

\section{جدول ا - توزيع فراوانى نسبى وضعيت دانث افراد

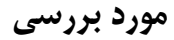

\begin{tabular}{|c|c|c|}
\hline درصد & تعداد & هِاسخ \\
\hline$\Delta \Delta / \bar{\epsilon}$ & 10. & ضعيف \\
\hline$m e / l$ & qr & متوسط \\
\hline $1 \cdot / \pi$ & $r \Lambda$ & خوب \\
\hline
\end{tabular}

بررسى نتايج مطروحه در خصوص نخرش افراد نسبت

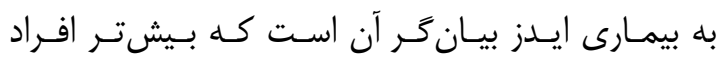

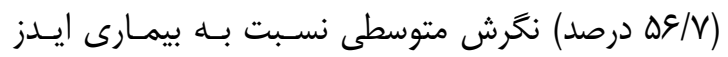
داشتند (جدول شماره r).

\section{جدول r- توزيع فراوانى نسبى وضعيت نكَرش افراد

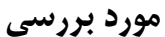

\begin{tabular}{|c|c|c|}
\hline درصد & تعداد & ياسخ \\
\hline Tr/T & AV & منفى \\
\hline$\Delta F / V$ & אטו & متوسط \\
\hline $11 / 1$ & r. & مثت \\
\hline
\end{tabular}

نتايج مطالعه در خصوص مقايسه آكاهى فرد نسبت به

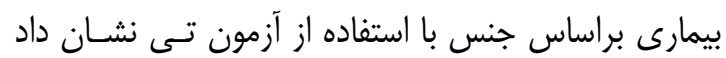

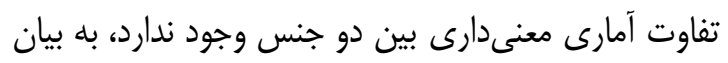

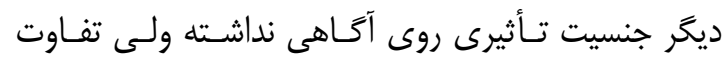

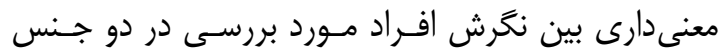

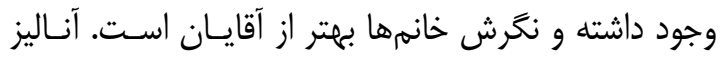

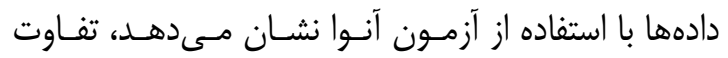

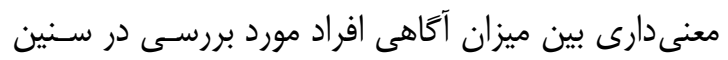

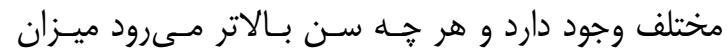

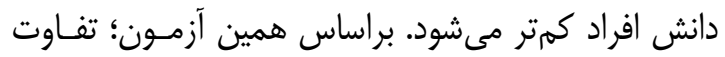

و نكرش بيماران مراجعه كنتده به دانشكده دنـدانيزشـكى

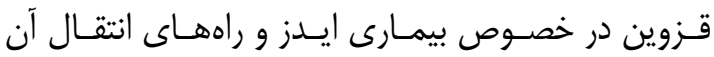

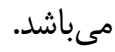

\section{جواد و روشها:}

ايــن مطالعـهـ توصــيفى - مقطعـى بـــا اســفاده از يرسشنامهاى كه توسط محقق و با استناد به يرسشنامـاهـ

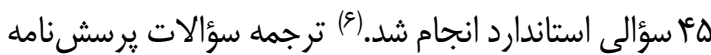
به تأييد متخصص بيمارىهـاى دهـان رسـيد و برخى از لاز

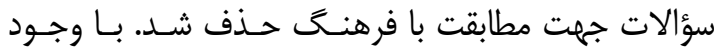

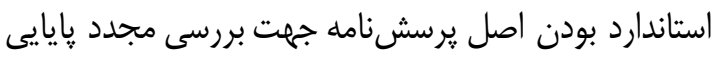

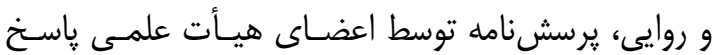
داده شد و با آلفاى كرونباخ \&/• مورد تأييد قرار كرفت. قسمت اول يرسشنامه شامل اطلاعات شخصى؛ سن، جنس، وضعيت تأهل، شغل، تحصيلات و سابقه ابـتلا بــهـ

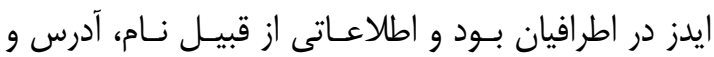

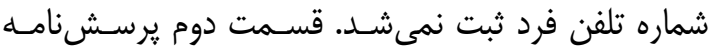

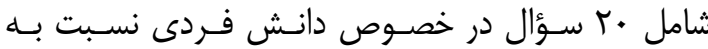

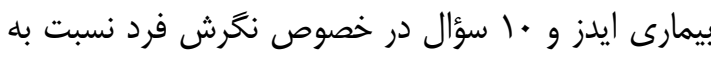
بيمارى ايدز بود. پاسخ سؤالات شامل؛ صحيح، نمىدانم و نادرست بود كه هر ياسخ درست فرد؛ دو، ياسخ غلط فـردي صفر و نمى دانم يك امتياز نمر هدهى شد. براساس نمرهدهى داسى

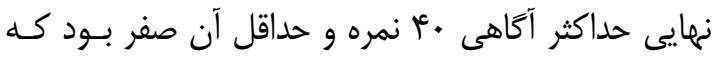

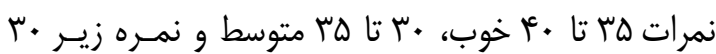

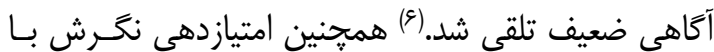

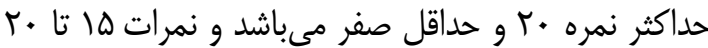

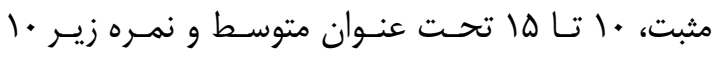
بلهعنوان نحَرش منفى نسبت به بيمارى تلقى شد. (9) معيـار

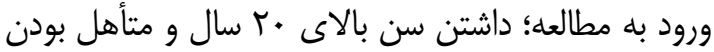

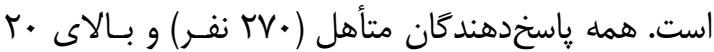

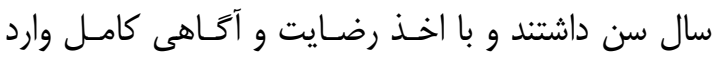
مطالعه شدند. دادههاى آمارى پِ از جمع آورى دادههـاى راى خام با استفاده از نرمافزار 19 SPSS و آزمونهاى آمـاري آنسارى أنسوا و تى مورد تجزيه و تحليل قرار كرفتند. 


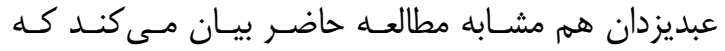

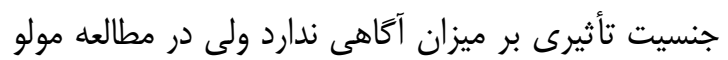

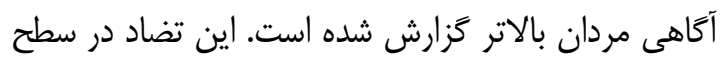

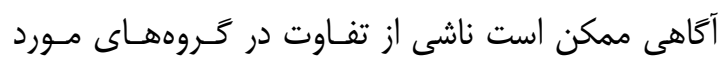

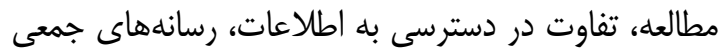

و مشاركت در نشستهاى مختلف ضدايدز باشد.و (1)

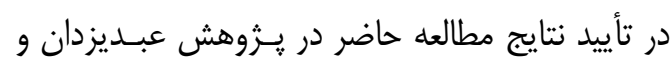

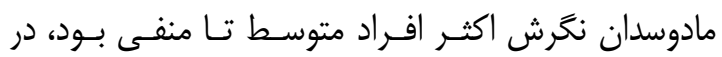
حالى كه مطالعه هان و مولو بهعلت تفاوت در جامعه مـورد العاد

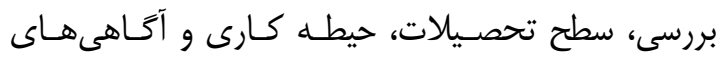

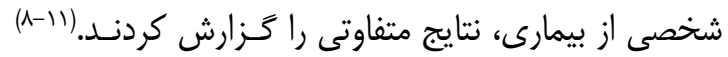

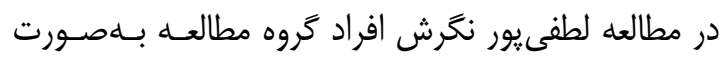
مثبت كزارش شد كه اين تفاوت با مطالعه حاضر مىتوانـــ

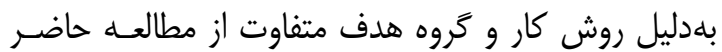
باشد. بهدليل

در مطالعه حاضر مشخص شد كه نخرش خانمها بهتر

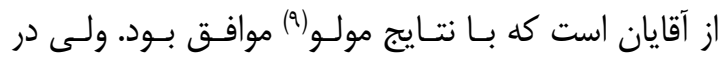

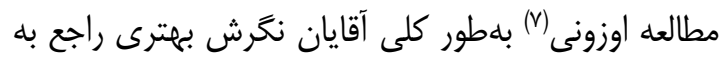

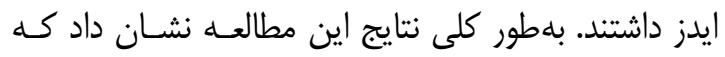

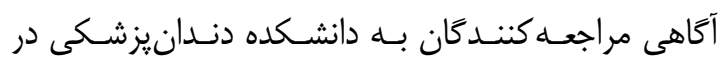

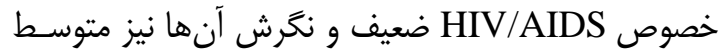

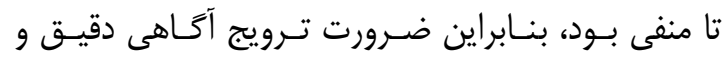

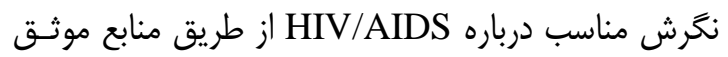

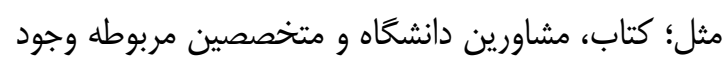

\section{مراجع:}

1. Bolla CR, Rao AR, Reddy Sh, Ravikumar BP. Knowledge regarding HIV/AIDS among secondary school students in Khammam town, Andhra Pradesh. Int J Res Dev Health 2013; 1(3): 103-8.

2. Sanjel K, Chalise HN. HIV/AIDS knowledge and perceptions among schoolgoing adolescents in Nepal's country side.
معنى دارى بين نمره نكَرش افراد مورد بررسى در سـين

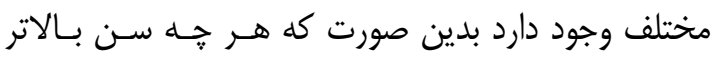

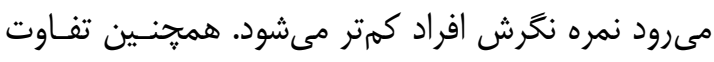

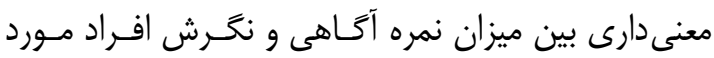

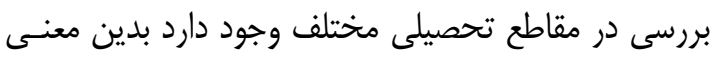

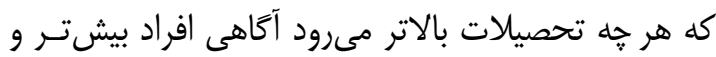
نحخرش آنها مثبت مى شودا.

\section{باحث و نتيجه تيرى:}

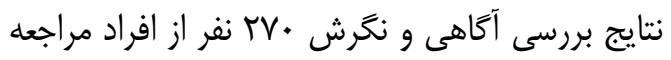

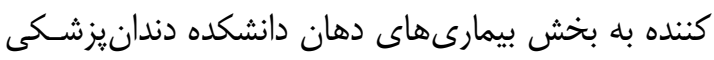

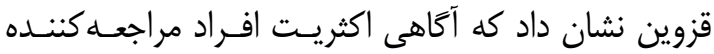

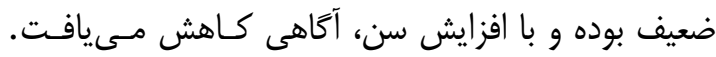

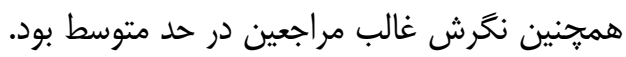

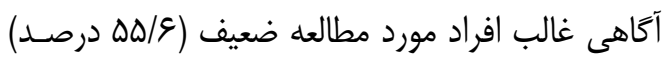

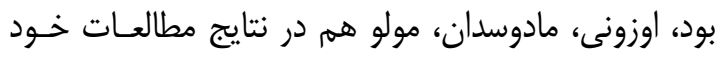

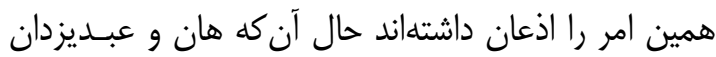

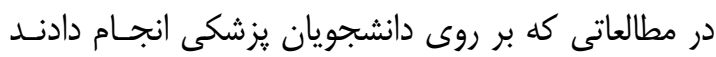

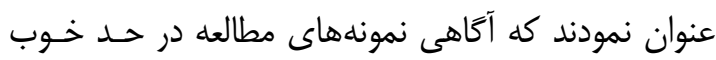

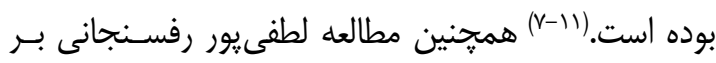
روى دانشجويان غيريزشكى نشان داد كه دانش آنهـا در

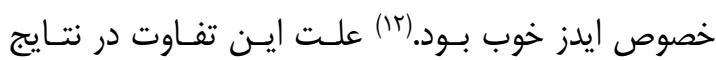

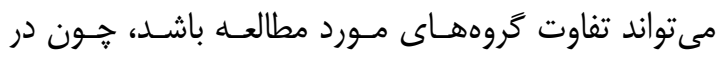

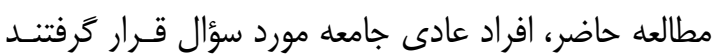
ولى انتظار مىرود كه دانشجويان يزشكى بــهعلت سـطح

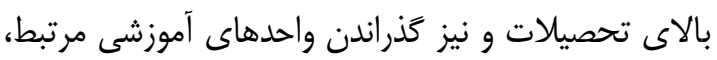

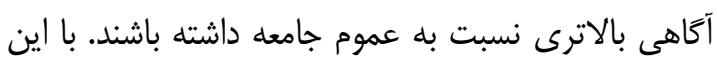

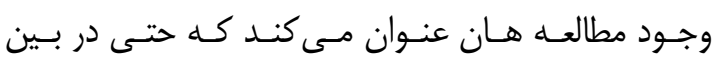

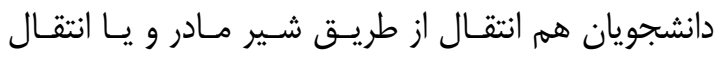

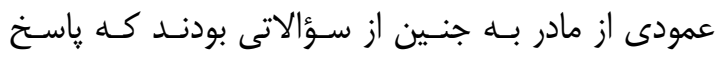

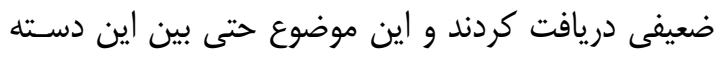
از افراد هم با غفلت روبـرو شــه اسـت. حتـى در مطالعـهـ عبديزدان هم نسبت قابل ملاحظـهـاى از ياسـخدهنـدان

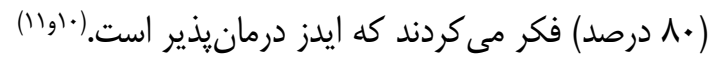


Asia-Pacific E-journal of Health Social Science 2013; 2(2): 1-4.

3. Petros P. Risk perception, HIV/AIDS related knowledge, attitude and practice of the university community: the case of Ethiopian Civil Service College. HIV AIDS Rev 2014; 13(1): 26-32.

4. Zafar M, Nisar N, Kadir M, Fatmi Z, Ahmed Z, Shafique K. Knowledge, attitude and practices regarding HIV/AIDS among adult fishermen in coastal areas of Karachi. BMC Public Health 2014; 14: 437. doi: 10. 1186/1471-2458-14-437.

5. Useh U, Keikepe A, Montshiwagae B, Mothoagae R, Senna D. Knowledge and attitude of pregnant women towards Mother to Child Transmission (MTCT) of HIV and AIDS in a local clinic in Mafikeng, South Africa. Ethno Med 2013; 7(3): 163-9. doi: 10. 1080/09735070.2013.11886457.

6. Carey MP, Morrison-beedy D, Johnson BT. The HIV-knowledge questionnaire: development and evaluation of a reliable, valid and practical self-administered questionnaire. AIDS Behav 1997; 1(1) 61-74. 7. Ouzouni $\mathrm{Ch}$, Nakakis K. HIV/AIDS Knowledge, attitude and behaviours of student nurses. Health Sci J 2012; 6(1): 129-50.

8. Madhusudan M, Mohammad I, Mahadeva Murthy TS, Shwetha N, Suresha DS. Impact of educational intervention in improvement of knowledge and attitude toward HIV/AIDS among rural college students. Int J Basic Appl Med Sci 2014; 4(1): 244-50.

9. Mulu W, Abera B, Yimer M. Knowledge, attitude and practices on HIV/AIDS among students of Bahir Dar University. Sci J Public Health 2014; 2(2): 78-86. doi: 10. 11648/j. sjph.20140202.16.

10. Ni H, Htet A. Knowledge and Attitude of HIV/AIDS Infection among Medical Students. Int J Collab Res Intern Med Public Health 2012; 4(4): 317-26.

11. Abdeyazdan Z, Sadeghi N. Knowledge and attitude toward AIDS/HIV among senior school students in Isfahan. Iran J Clin Infect Dis 2008; 3(2): 93-8.

12. Lotfipur Rafsanjani SM, Ravari A, Akbarinasab J. Knowledge, attitude and practice of non-medical students to the ways of transmission and prevention of AIDS in Rafsanjan city. Iran J Nurs Res 2011; 6(22): 31-9. [In Persian] 